\title{
Physical geography and closed loop recycling
}

\author{
Michael A. FULLEN ${ }^{1}$
}

\begin{abstract}
There is a growing body of research projects spanning over three decades that have provided insights into the concept of waste management, a topic standing in the focal point of environmental issues. In this paper, the 'SHASEA Project,, 'BORASSUS Project,' Yuanyang Project' and 'Cradle to Cradle BIZZ Project' are summarized and integrated to present a revised philosophical view that nature has no concept of 'waste.'The 'Sustainable Highland Agriculture in South-East Asia' (SHASEA) Project, funded by the European Union, was established to promote sustainable agro-environmental development in the highlands of South-East Asia. The Project examined the effectiveness of selected agronomic and soil conservation treatments by using both modified and novel cropping practices within small farmer-managed fields. The EU-funded BORASSUS Project evaluated the long-term effectiveness of biological geotextiles in controlling soil erosion and assessing their sustainability and economic viability. Biological geotextiles offer potentially novel bioengineering solutions to environmental problems (e.g. soil conservation, sustainable plant production and improved ecosystem management). Biogeotextiles may provide socio-economic platforms for sustainable development. A complex and sustainable agro-environmental system of terraced rice paddy fields in Yuanyang developed by the Hani minority people of Yunnan Province was the basis of an illuminating project which teaches us many lessons on waste management, the 'Agro-environmental sustainability of the Yuanyang rice terraces of Yunnan Province, China'. The Hani people have maintained this intricate and elaborate system for over 1,300 years. If we can understand how this system is sustained, we can learn lessons which hopefully can be applied more generally. The innovative approach of 'Cradle to Cradle' (C2C) technology promotes and develops closed loop recycling. At the end of a useful life time, $\mathrm{C} 2 \mathrm{C}$ items are disassembled and reassembled for other uses. Lessons from the ' $\mathrm{C} 2 \mathrm{C} B \mathrm{BIZ}$ ' Project (funded by the EU 'INTERREG IVB North West Europe Programme) are also reviewed in this study.
\end{abstract}

Keywords: biogeotextiles, cradle to cradle, recycling, resources, waste

\section{The SHASEA Project}

To promote sustainable agro-environmental development in the highlands of South-East Asia, an international multidisciplinary research team, funded by the European Union, examined the effectiveness of selected agronomic and soil conservation treatments (EU Contract Number ERBIC18 CT98 0326) (Fullen, M.A. 2004). The team used both modified and novel cropping practises within farmer-managed small fields on a natural and representative catchment (Wang Jia) in the highlands of Yunnan Province, China (25⒉ $\left.8^{\prime} \mathrm{N}, 102^{\circ} 53^{\prime} \mathrm{E}\right)$.

The 'Sustainable Highland Agriculture in South-East Asia' (SHASEA) Project involved five co-ordinated work-packages: (i) background agricultural and environmental assessment of Wang Jia Catchment; (ii) implementation and evaluation of modified and novel watershed cropping systems for wheat, maize (corn) and soybean; (iii) cost-benefit analyses of the socio-economic impacts of cropping practice changes; (iv) comparative scientific evaluation of cropping techniques in the highlands of northern Thailand at Pang Mapa, Mae Hong Son Province (19³ $\left.33^{\prime} \mathrm{N}, 98^{\circ} 12^{\prime} \mathrm{E}\right)$ and (v) dissemination of project outcomes and establishment of training programmes for best practise in highland rural development.

From each of these, project lessons for promoting sustainable agro-environmental

\footnotetext{
${ }^{1}$ Faculty of Science and Engineering, The University of Wolverhampton, Wolverhampton WV1 1LY, UK.

E-mail: m.fullen@wlv.ac.uk
} 
development in tropical and subtropical highlands include: (a) the importance of recognizing the value of both 'North-South' and 'South-South' co-operation in development projects; (b) integrating local communities as full partners in the research programme; (c) matching the different 'time horizons' of the various stakeholders and $(d)$ developing multidisciplinary teams, which included both biophysical scientists and socio-economists.

During 1999, based on field and plot experience, the team designed a composite maize cropping system to maximize both crop yield and soil/water conservation, known as the 'Integrated Contour Cultivation, Plastic and Straw Mulch Treatment' (INCOPLAST) (Figure 1).

The system combines contour cultivation, straw mulch and plastic mulch (Fullen, M.A. 2004). To establish early crop growth and to maximize yield, irrigation water is applied prior to monsoon rains. The INCOPLAST system is then installed, to both maximize yield (by addition of plastic mulch) and conserve soil, water and associated nutrients (by installation of contour cultivation and straw mulch). Ridge morphology is shaped to route water towards the maize roots beneath the plastic mulch. Experiments proved soil bulk densities beneath the plastic mulch remained low throughout the growing season, thus promoting easier root penetration, higher aeration porosity, higher infiltration and lower runoff rates (Subedi, M. et al. 2009). Plot borders were grassed, to retain soil and water within the arable fields. The INCOPLAST system proved effective for soil and water conservation and significantly increased crop productivity (WANG, SHuHur 2003) (Table 1).

\section{The BORASSUS Project}

The three-year plus (1 July 2005--28 February 2009) EU-funded BORASSUS Project (contract no. INCO-CT-2005-510745) evaluated the long-term effectiveness of biological geotextiles in controlling soil erosion and assessing their sustainability and economic viability (Fullen, M.A. et al. 2011). Field and laboratory studies indicated that utilization of biological geotextiles constructed from palm-leaves and other selected organic materials are an ef-

Fig.1. The INCOPLAST (INtegrated COntour cultivation with PLastic And wheat STraw mulch) system used on experimental fields in Wang Jia Catchment

Table 1. Grain weight (t/ha, corrected to 13\% moisture) from Wang Jia Catchment plots over three seasons

\begin{tabular}{l|c|c|c|c|c|c}
\hline Treatments $^{*}$ & 1999 & Increasing \% vs. D & 2000 & Increasing \% vs. D & 2001 & Increasing \% vs. D \\
\hline $\mathrm{D}$ & $7.26 \mathrm{a}$ & 0.0 & 7.82 & 0.0 & $6.21 \mathrm{a}$ & 0.0 \\
$\mathrm{C}$ & $8.08 \mathrm{a}$ & 11.2 & 8.81 & 12.7 & $6.66 \mathrm{a}$ & 7.2 \\
$\mathrm{C}+\mathrm{P}$ & $11.19 \mathrm{~b}$ & 54.0 & 9.49 & 21.4 & $8.27 \mathrm{~b}$ & 33.2 \\
$\mathrm{C}+\mathrm{P}+\mathrm{S}$ & $10.80 \mathrm{~b}$ & 48.7 & 9.70 & 24.0 & $8.42 \mathrm{~b}$ & 35.5 \\
$\mathrm{~F}$ & 37.46 & - & 1.49 & - & 16.17 & - \\
$\mathrm{p}$ & $<0.01$ & - & 0.28 & - & $<0.01$ & - \\
LSD & $1.39 \mathrm{t}$ & - & - & - & $0.88 \mathrm{t}$ & - \\
\hline
\end{tabular}

*Different letters denote significant $(\mathrm{P}<0.05)$ differences. $\mathrm{D}=$ Downslope cultivation without mulch; $\mathrm{C}=$ Contour cultivation without mulch; $\mathrm{C}+\mathrm{P}=$ Contour cultivation with polythene mulch; $\mathrm{C}+\mathrm{P}+\mathrm{S}=\mathrm{Contour}$ cultivation with polythene and wheat straw mulch (INCOPLAST). Source: WANG, Shuhur 2003. 
fective, sustainable and economically viable soil conservation technique. These studies progressed in 10 countries, both in the 'industrial north' (in Europe) and in the 'developing south' (Africa, South America and South East Asia). The studied countries in the 'developing south' included Brazil, China, Gambia, South Africa, Thailand and Vietnam. The 'industrial north' countries included Belgium, Hungary, Lithuania and the UK.

Biological geotextiles offer potentially novel bioengineering solutions to environmental problems, including technologies for soil conservation, sustainable plant production and use of indigenous plants, improved ecosystem management by decreasing deforestation, improving agroforestry and cost-effective biogeotextile applications in diverse environments. Biogeotextiles may provide socio-economic platforms for sustainable development and the benefits for developing countries may include poverty alleviation, engagement of local people as stakeholders, employment for disadvantaged groups, small and medium enterprise (SME) development, earning hard currency, environmental education and local community involvement in land reclamation and environmental education programmes. These benefits are achieved through:

(i) promotion of sustainable and environmentally friendly palm-agriculture to discourage deforestation, promoting both reforestation and agroforestry,

(ii) construction of biogeotextiles enabling development of a rural labour-intensive industry, particularly encouraging employment of socially disadvantaged groups, and

(iii) export of biogeotextiles to industrialised countries could earn hard currency for developing economies, based on the principles of fair trade.

The BORASSUS Project offers many insights into sustainability and waste issues, especially in São Luís, Maranhão State, North-East Brazil (GuerrA, A.J.T. et al. 2014). This work-package assessed the effects of biological geotextiles, constructed from the palm leaves of Mauritia flexuosa (Buriti), in the reclamation of a large ( 10 m deep) gully.
Accelerated erosion in Sacavém gully (São Luís) is enhanced by intense rains, acting in combination with vegetation clearance and the erodible sandy soil texture. Intense human action, with inappropriate soil use and irregular settlement, also plays a very important role in promoting gully erosion. The gully was stabilized using a combination of land-sculpturing, planting and the application of geotextiles. Only one month after the rehabilitation work was completed, the area was exposed to intense erosive rains (one-month total $753.7 \mathrm{~mm}$, with a recurrence interval of $\sim 60$ years). Vegetation resisted erosion and the Buriti geotextiles seemed to have achieved the main aim of arresting erosion and rehabilitating the gullied area.

Integrating the results indicate positive effects of using biological geotextiles, as they offer potential for sustainable development and soil conservation. Furthermore, they can also be used for economic development, creating jobs and reducing poverty in poor urban areas. The higher-quality Buruti leaves are used for the handicraft manufacture of gift items for tourists (e.g. handbags, purses, wallets and hats). Coarse discarded leaves are used to construct the biogeotextiles. On decomposition, the leaves input nutrients into the soil, especially potassium (K), magnesium (Mg), calcium (Ca) and sulphur (S).

The leaves can also be burned and added as an ash-fertilizer to soils. The fruit is used to make fruit juice, ice cream and alcoholic beverages. The palm oil is used for skin care and may be useful for preventing skin cancer. On the death of the palm trees, the wood can be carved into boxes, statues and other trinkets for sale to tourists. Therefore, soil conservation and economic development are compatible and the Sacavém gully may well be an excellent exemplar of a zero-waste closed loop recycling system.

Long-term monitoring at Sacavém will enable thorough evaluation of the effectiveness of an integrated soil conservation programme on both erosion rates and processes and sustainable economic development. The ongoing site development can be moni- 
tored via the 'Laboratory of Environmental Geomorphology and Land Degradation' of the Federal University of Rio de Janeiro (LAGESOLOS) web site: http://www.lagesolos.ufrj.br (accessed 09/11/15).

\section{The Yuanyang Project}

One of the most illuminating projects which teaches us many lessons on waste management is the study on the 'Agro-environmental sustainability of the Yuanyang rice terraces of Yunnan Province, China' (Colinet, G. et al. 2011; Fullen, M.A. 2014). The Hani minority people of Yunnan Province (SouthWest China) have developed a complex and sustainable agro-environmental system of terraced rice paddy fields in Yuanyang $\left(22^{\circ} 49^{\prime}-23^{\circ} 19^{\prime} \mathrm{N}, 102^{\circ} 27-103^{\circ} 13^{\prime} \mathrm{E}\right)$. The Hani people have maintained this intricate and elaborate system for over 1,300 years, with some 3,000 terraces covering about 11,000 hectares. Hence, during the Ming Dynasty (1368-1644), an Emperor awarded the Hani people the title of "Magic Mountain Sculptors" for "building their ladders to Heaven." However, geographic isolation and proximity to the, until recently, politically-sensitive border with Vietnam, has meant the Yuanyang terraces have attracted scant scientific attention. If we can understand how this system is sustained, we can learn lessons which hopefully can be applied more generally.

The sustainability of the system seems to be the result of complex interplays between cultural, agronomic and environmental factors. These include the cultural and spiritual beliefs of the Hani people, a hydrogeological system which provides ample water resources, the maintenance of genetic diversity within the dominant rice cropping agro-ecosystem and the operation of complex fertigation practises. Distilling and understanding the 'secrets' of the Hani people and their terraces should enable broader application and dissemination of the principles of sustainability. Currently a joint Chinese-European team are working towards a greater understanding of these lessons. The research team postulate that these lessons will have some global applicability for agro-environmental sustainability. Identified lessons relate to resource optimization, landscape multi-functionality and cultural attitudes.

Landuse within Yuanyang is zoned on the basis of ecological principles. Upland grassland progresses downslope into forest and then in a downslope sequence into tea plantations, bamboo woodland and rice terraces. Grasslands are used for the grazing of water buffalo, while wooded areas provide timber (deciduous, pine and bamboo) and food (mushrooms, wild vegetables and honey). The local Yunnan pine (Pinus yunnanensis) provides an excellent source of timber. Furthermore, the forest is very effective in conserving soil and water and releases high quality water from the upper to lower slopes. Besides providing rice, the perennially wet paddy fields provide food for domestic consumption (carp, eels, mudfish, ducks, frogs and snails) and weeds for pig-feed (Photo 1). Thus, there is multifunctional use of each ecoagricultural zone, which ensures optimum use of resources, effective recycling of materials and minimal waste. Often, the net waste from these subsystems is virtually zero.

The Hani people have a unique cultural system that reveres the land. The Hani religion embraces polytheism and the worship of nature. They pay particular devotion to the 'forest god,' which is perceived as the source of life-giving water. Deforestation is considered a religious violation and the Hani people actively teach their children to respect the forest.

This concept significantly contributes to forest conservation and ecosystem stability. In general, we can learn much from these positive environmental attitudes, in terms of improving public understanding and appreciation of land resources (land literacy) and agro-environmental education at multiple levels (school, college and university). The ancient ballads (poetic songs) of the Hani people are highly instructional in terms of maintaining the sustainability of agro-environmental systems. 


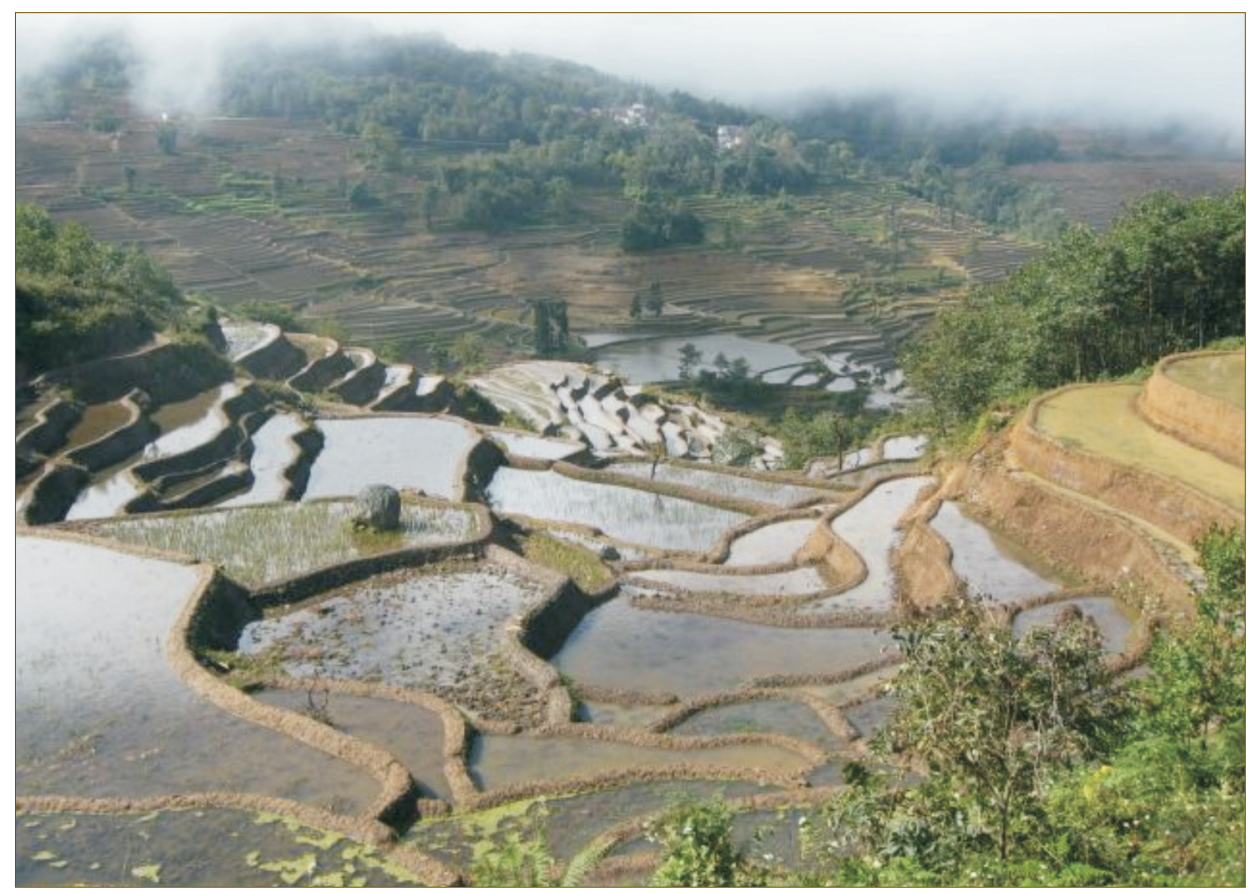

Photo 1. The rice terraces of Yuanyang, Yunnan Province, P.R. China (Photo by FulLen, M.A. on 23 Oct. 2009)

\section{The Cradle to Cradle BIZZ Project}

Critical analysis of the concept of 'waste' is integral to 'Cradle to Cradle' (C2C) technology, which is an innovative approach that promotes and develops closed loop recycling. At the end of a useful life time, C2C items are disassembled and reassembled for other uses. The aim is that materials are not downgraded, but rather at least retain the same grade with the objective of upgrading materials. C2C was developed by Michael Braungart and William McDonough in the 1980s and has progressively gained increased attention and interest (Braungart, M. and McDonough, W. 2009). There are three guiding principles:

1. 'Waste equals food.' In nature there is no concept of waste; when any material has served its purpose, it is used by something else.

2. 'Use solar income.' Solar energy is effectively infinite and if we can successfully harness it, then we have an infinite energy source. Solar energy indirectly powers the wind, by creating air pressure differences which generate wind. Solar energy from the geological past is stored underground. Thus, solar energy, wind power and geothermal energy systems are interpreted as 'solar income.'

3. 'Celebrate diversity.' Ecological systems (flora and fauna) adapt to the complexity of their environment to survive and thrive. Therefore, if we mimic diverse ecological systems, we can strengthen our social, economic and environmental sustainability.

Our global resources are running out. We all know that something has to change, in order to keep our planet habitable. The C2C philosophy aims for a beneficial future footprint by continuing material flows, using renewable energy and creating ecological, social and economic diversity.

The University of Wolverhampton (UoW) is a partner in the 'C2C BIZZ' Project. The Project involves 11 partners from six EU countries (Belgium, France, Germany, Luxembourg, The Netherlands and the UK). 
The partners include public bodies, research institutes, private companies and universities. The Project is funded by the 'INTERREG IVB North West Europe Programme of the European Union.' UoW is collaborating in the C2C BIZZ Project, which has the objective to enhance the implementation of $\mathrm{C} 2 \mathrm{C}$ technology on new and existing business sites in North West Europe. The aim is to mix functionalities, to promote co-operation and collaboration of on-site companies and develop an attractive environment, by using resources in different and innovative ways.

By its very nature $\mathrm{C} 2 \mathrm{C}$ is multidisciplinary and so multidisciplinary teams can effectively work together, including engineers, scientists, environmentalists, economists, ecologists etc. In November 2014, the team published its main output; that is the 'Guide to Cradle to Cradle Business Sites.' The Guide is freely available on the C2C web site: http:// www.c2cbizz.com/ (accessed 09/11/15).

An important concept implicit in $\mathrm{C} 2 \mathrm{C}$ technology and philosophy is that, in reality, there is no such thing as 'waste.' 'Waste' from one process or material becomes a resource for other process(es) or material(s). Perhaps we should view 'waste' as 'resources.' There are several excellent examples of this changed philosophy. One is 'AirCarbon,' where atmospheric carbon in the form of methane $\left(\mathrm{CH}_{4}\right)$ is used to produce plastics, especially plastic mobile telephone covers: http://newlight.com/aircarbon/ (accessed 09/11/15). Another is the use of sewage sludge solids to make light-weight building aggregates (D. Newport, University of East London, pers. comm. 2013).

\section{Conclusions}

It is timely that we progress to imitate 'nature' and recognize there is really no such thing as waste. We can develop effective 'closed-loop recycling systems' which minimize waste or may even generate zero waste. Indeed, as we advance to 'cradle to cradle' systems, we can recognize output from one system as a resource for another and that waste can become a resource.
Acknowledgement: Thanks to Dr S. SuRESH for preparing Figure 1.

\section{REFERENCES}

Braungart, M. and McDonough, W. 2009. Cradle to Cradle: Remaking the Way We Make Things. London, Vintage Books.

Colinet, G., Koulos, K., Wu Bozhi, Li Yongmei, LaCroix, D., Su Youbo, Chapelle, J., Fullen, M.A., Hocking, T. and Воск, L. 2011. Agro-pedological assessment of the traditional Yuanyang rice terraces of Yunnan Province, China. Journal of Resources and Ecology 2. (3): 289-299.

Fullen, M.A. 2004. The development of sustainable cropping systems on red soils in the highlands of South China. In The Red Soils of China: Their Nature, Management and Utilization. Eds.: Wilson, M.J., Li, Zhenli and XIAOE, YANG. Dordrecht, Springer, 261-274. (on behalf of SHASEA).

FulLen, M.A. 2014. Agro-environmental sustainability of the Yuanyang rice terraces of Yunnan Province, China. Espaço Aberto, PPGG-UFRJ 4. (1): 35-42.

Fullen, M.A., Subedi, M., Booth, C.A., Sarsby, R.W., Davies, K., Bhattacharyya, R., Kugan, R., Luckhurst, D.A., Chan, K., Black, A.W., Townrow, D., James, T., Poesen, J., Smets, T., Kertész, Á., Tóth, A., Szalai, Z., JaKab, G., Jankauskas, B., Jannkauskiene, G., Büchmann, C., Paterson, G., Mulibana, E., Nell, J.P., Van der Merwe, G.M.E., Guerra, A.J.T., Mendonça, J.K.S., Guerra, T.T., Sathler, R., Bezerra, J.F.R., Peres, S.M., Zheng YI, Li Yongmei, Tang Li, Panomtarachichigul, M., Peukrai, S., Dao Chau Thu, Tran Huu Cuong, Truong Thi Toan, Jonsyn-Ellis, F., Sylva, J.Z., Cole, A., Mulholland, B., Dearlove, M., Corkill, C. and TomLInson, P. 2011. Utilizing biological geotextiles: introduction to the BORASSUS Project and Global perspectives. Land Degradation and Development 22. 453-462.

Guerra, A.J.T.,Bezerra,J.F.R., Fullen, M.A., MendonçA, J.K.S. and Jorge, M.C.O. 2014. The effects of biological geotextiles on gully stabilization in São Luís, Brazil. Natural Hazards. DOI 10.107/sl 1069-014-1449-0

Subedi, M., Hocking, T.J., Fullen, M.A., McCrea, A.R. and Milne, E. 2009. Lessons from participatory evaluation of cropping practices in Yunnan Province, China: overview of the effectiveness of technologies and issues related to technology adoption. Sustainability 1. 628-661. Open on-line access at: (accessed 09/11/15).

WANG SHuHuI 2003. Cultivation practices, maize and soybean productivity and soil properties on fragile slopes in Yunnan Province, China. Ph.D. thesis, The University of Wolverhampton (UK). 